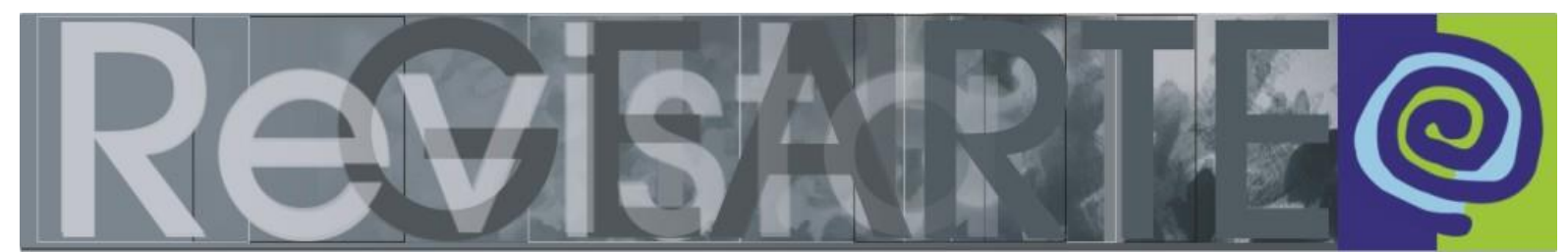

ISSN 2357-9854 | e-ISSN 2596-3198 (online)

\title{
Artes Visuais na Pedagogia: atelier de criação de bonecos de pano
}

\author{
Analice Dutra Pillar (iD \\ (Universidade Federal do Rio Grande do Sul — UFRGS, Porto Alegre/RS, Brasil) \\ Rosana Fachel de Medeiros \\ (Secretaria Municipal da Educação de Canoas - SME, Canoas/RS, Brasil)
}

\begin{abstract}
RESUMO - Artes Visuais na Pedagogia: atelier de criação de bonecos de pano - A indústria de brinquedos produz uma infinidade de bonecos de plástico, que choram, andam e cantam. A publicidade estimula o consumo, transformando-os em objetos de desejo das crianças. Os bonecos, que em sua maioria são padronizados, acabam indicando um modo de ser. A criação de bonecos de pano se contrapõe ao consumo de brinquedos e é uma possibilidade de inventar algo singular com outros corpos, cabelos, roupas. Este texto enfoca a relevância da arte, ao propiciar a criação de bonecos a estudantes do curso de Pedagogia. Aborda ateliers realizados com diferentes turmas, em mais de duas décadas, que mostram a diversidade dos trabalhos e suas relações com criações da arte contemporânea.
\end{abstract}

\section{PALAVRAS-CHAVE}

Educação e Artes Visuais. Pedagogia. Atelier de criação. Bonecos de pano. Formação de professores.

\begin{abstract}
Visual Arts in Pedagogy: rag doll creation workshop - The toy industry produces a multitude of plastic dolls that cry, walk and sing. Advertising stimulates consumption, transforming them into objects of desire for children. The dolls, which are mostly standardized, end up indicating a way of being. The creation of rag dolls is opposed to the consumption of toys and is a possibility of inventing something unique with other bodies, hair, clothes. This text focuses on the relevance of art, by providing the creation of puppets to students in the Pedagogy course. It deals with workshops carried out with different groups, over more than two decades, that show the diversity of the works and their relationship with contemporary art creations.
\end{abstract}

\section{KEYWORDS}

Visual Art Education. Pedagogy. Creation workshop. Rag dolls. Teacher training.

RESUMEN - Artes visuales en la Pedagogía: taller de creación de muñecos de trapo - La industria del juguete produce una infinidad de muñecos de plástico, que lloran, caminan y cantan. La publicidad estimula el consumo transformándolos en objetos de deseo para los niños. Los muñecos, que en su mayoría están estandarizados, terminan indicando una forma de ser. La creación de muñecos de trapo se opone al consumo de juguetes y es una posibilidad de inventar algo único con otros cuerpos, cabellos, ropas. Este texto se centra en la relevancia del arte al proporcionar la creación de muñecos a los estudiantes del curso de Pedagogía. Se trata de talleres realizados con diferentes colectivos, a lo largo de más de dos décadas, que muestran la diversidad de las obras y su relación con las creaciones artísticas contemporáneas.

PALABRAS CLAVE

Educación Artística. Pedagogía. Taller de creación. Muñecas de trapo. Formación de profesores. 


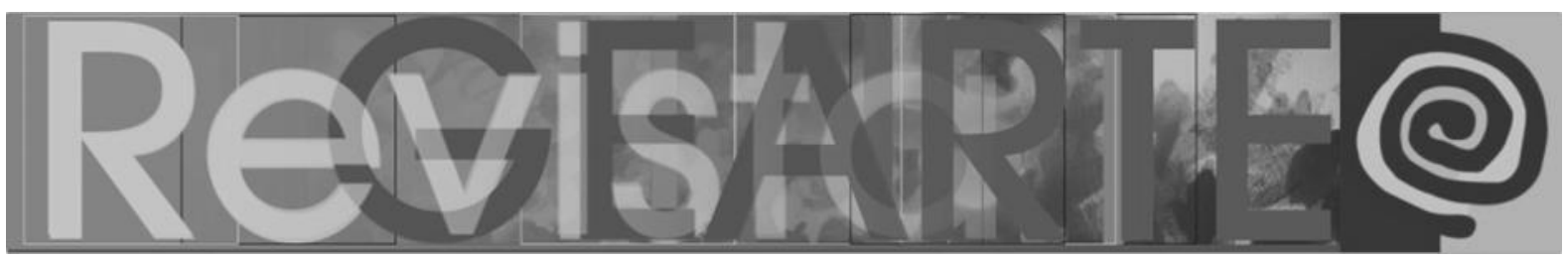

Ter a garantia do professor habilitado em uma linguagem artística em todas as escolas brasileiras é uma perspectiva possível, mas ainda distante. Contudo, entendemos e defendemos que a formação do pedagogo no tocante à arte, [...] é absolutamente necessária. (ARAÚJO, 2015, p. 56)

A diversidade dos bonecos de pano sempre nos encantou e ao dar aulas de artes, seja para crianças, seja para adolescentes ou, até mesmo, para adultos, as propostas de construção de brinquedos com sucata, com papel ou com tecido têm sido algo muito divertido e prazeroso. Neste texto, enfocaremos, em especial, a criação de bonecos de pano com estudantes da disciplina de Educação e Artes Visuais no curso de Licenciatura em Pedagogia da Faculdade de Educação da Universidade Federal do Rio Grande do Sul. Abordaremos ateliers realizados com diferentes turmas ao longo de mais de duas décadas.

\section{Bonecos como objetos de desejo}

No cotidiano das crianças, os brinquedos, em especial os bonecos, são objetos que as fascinam e viram objetos de desejo. Bonecos que choram, que falam, que se movem, que parecem bebês ou adultos. "Excitação e sensações é que são vendidas, e é experiência vivida que se compra, assemelhando-se todo consumidor, mais ou menos, a um colecionador de experiências', desejoso de que se passe alguma coisa aqui e agora." (LIPOVETSKY, 2007, p. 68). A indústria de brinquedos oferece uma infinidade de bonecos de plástico e, através da publicidade, incentiva o consumo ou o hiperconsumo de tais produtos.

Importa repensarmos esta cultura do consumo, do descarte, da busca incessante por novas sensações e novas experiências considerando que a felicidade está na aquisição de uma novidade que logo se tornará obsoleta. Bauman (2008, p. 29) diz que "[...] o consumismo hoje não se define pela acumulação de coisas, mas pelo breve gozo dessas coisas." Um hiperconsumo que carrega consigo a ideia de que é preciso ter o último lançamento do mercado para se estar atualizado, incluído. "A sociedade do hiperconsumo é marcada tanto pela progressão dos sentimentos de exclusão social quanto pela acentuação dos 


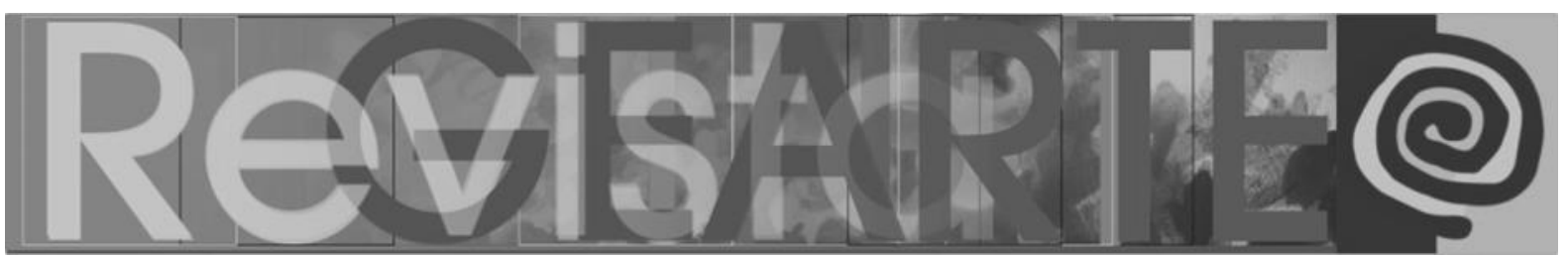

desejos de identidade, de dignidade e de reconhecimento individual." (LIPOVETSKY, 2007, p. 192).

Muitos desses bonecos são padronizados, isto é, têm um modelo de corpo, um tipo de cabelo, de cor de pele, o que acaba indicando um modo de ser. A Barbie, uma das bonecas mais difundidas ${ }^{1}$ entre as crianças, diferente dos bonecos bebês, é uma jovem. A esse respeito Oliveira (2001, p. 159) observa que se trata, então, de uma "[...] companheira mais velha, aquela que faz junto e mais ainda, aquela que ensina a fazer. Mas a fazer o quê? A única tarefa da mocinha esguia é manter a sua plástica inalterada para nela e com ela desfilar o seu guardaroupa sempre a ser atualizado."

Criada em 1959, a Barbie original é uma boneca loira, de cabelos compridos, alta, com corpo esguio, longas pernas, cintura fina, seios e bumbum bem modelados. María Acaso (2006, p. 31) menciona que a Barbie "[...] modela as mentes tanto das meninas, que quando adultas querem ser com ela, como dos meninos, que idealizam suas companheiras jovens, magras e loiras". E a autora continua dizendo que "[...] o cabelo, a cintura e os músculos [da Barbie] reproduzem um ideal impossível de alcançar e enviam duas mensagens concretas: a supremacia da raça branca e a condição feminina como objeto sexual." (ACASO, 2006, p. 31). Trata-se, assim, de uma grande narrativa visual que transmite uma visão do feminino.

Em 1968, foi produzida a primeira Barbie negra e, depois, surgiram outros modelos procurando mostrar a diversidade de etnias. Em 2016, a Mattel ${ }^{2}$, para comemorar os 57 anos de Barbie, criou 33 modelos da boneca, com quatro tipos de corpo - alta, baixa, curvilínea, original - e acrescentou, também, diferentes tons de pele, cores de olhos, cores de cabelo, formatos de rosto, penteados e acessórios. Em 2019, a Mattel anunciou a inclusão de duas bonecas com deficiência física, uma cadeirante e outra com prótese na perna, como parte da comemoração de 60 anos da Barbie $^{3}$. 


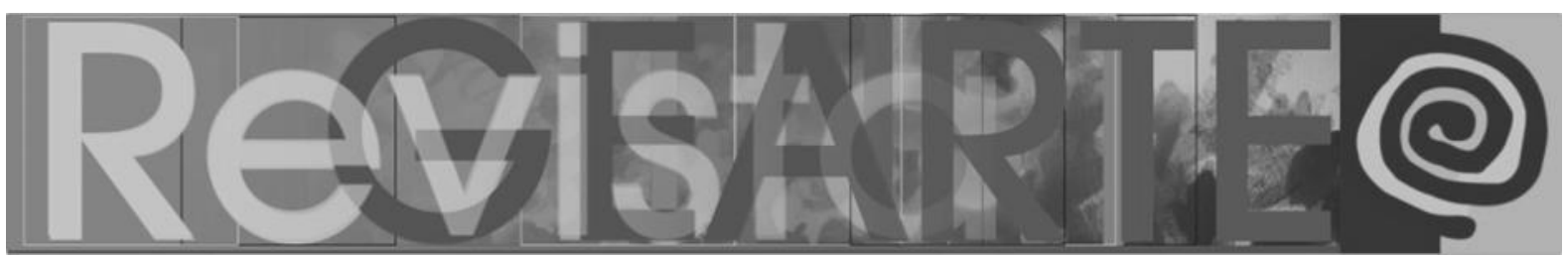

Nos últimos anos, surgiram, no mercado, outros bonecos com diferentes tipos físicos e com características étnicas diversas, para que as crianças se sintam representadas. No entanto, ainda há um predomínio no mercado de bonecos brancos em diferentes países e culturas, mesmo em países em que a população é, em sua maioria, negra, como em Moçambique. Nesse contexto, a criação de bonecos de pano vai na contramão do consumo de brinquedos prontos e é uma possibilidade de inventar algo singular com outros tipos de corpos, de cabelos e de roupas, trazendo as especificidades de cada pessoa. Isso porque "[...] qualquer enfoque do ensino da arte deve ter como base a cultura ou culturas às quais pertence a pessoa que aprende."4 (CONFERÊNCIA MUNDIAL SOBRE LA EDUCACIÓN ARTíSTICA, 2006, p. 5 - tradução nossa). Interessa-nos, então, ressaltar as singularidades de cada pessoa, de cada comunidade, de cada cultura, através de uma atividade muito realizada em locais em que os brinquedos industrializados são escassos - ou mesmo inexistem - e trazer como alternativa a confecção de bonecos de pano.

\section{Criação de bonecos de pano}

Uma das propostas que realizamos na disciplina Educação e Artes Visuais ${ }^{5}$ é o atelier de criação de bonecos de pano, com o objetivo de que os estudantes possam inventar bonecos para depois propiciarem essa atividade a seus futuros alunos. No caso de crianças, durante a confecção dos bonecos, está sendo explorado o esquema corporal e a brincadeira. A criação de famílias e de histórias com os personagens é uma decorrência. Já os adolescentes e adultos, podem fazer bonecos para vender ou ainda para doar às crianças. Existem escolas que instituíram O Dia do Brinquedo Inventado, como uma forma das crianças, tanto aquelas que possuem muitos brinquedos com tecnologias atuais como as que não tem acesso aos brinquedos industrializados, criarem seus bonecos, brinquedos e jogos. 


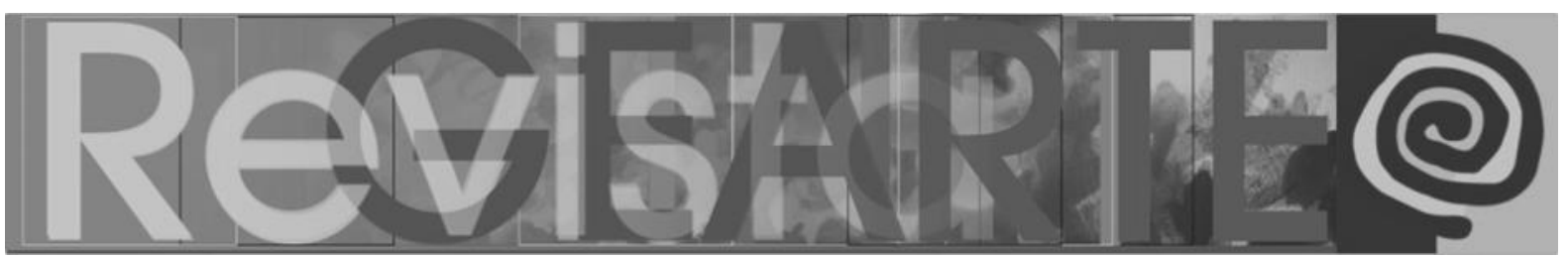

$\mathrm{Na}$ disciplina, o convite aos estudantes se dá através do chamamento: vamos criar bonecos? São mostrados bonecos de diversos lugares, feitos com materiais variados: uns somente com lãs, outros com fuxicos, com tecidos e caixas. Não há moldes ou tutoriais de como fazer. As figuras 1 a 8 mostram alguns desses bonecos.

Figuras 1 a 8 - Bonecos de pano de diferentes países, cidades, lugares
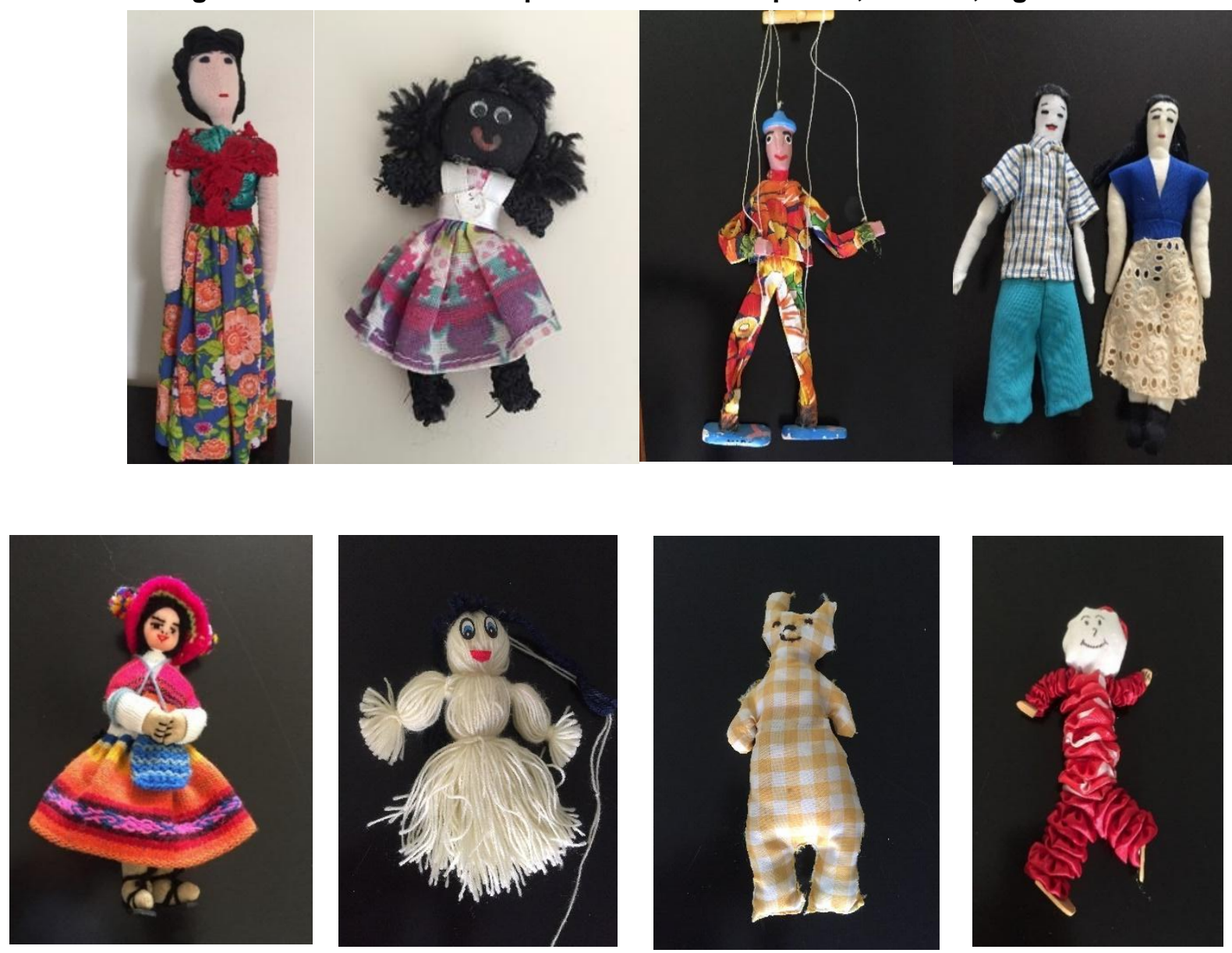

Fonte: Arquivo das autoras, 2020.

Com aproveitamento de tecidos, meias, botões, linhas, agulhas, lãs, fitas, lantejoulas, cola quente e jornais, os estudantes vão montando e construindo seus bonecos com fragmentos de materiais de contextos diversos. Uma possibilidade é começar amassando jornal para formar a cabeça do boneco e cobri-la com uma meia ou tecido. O mesmo processo pode ser feito com jornal e meia ou tecido para o corpo e para os membros superiores e inferiores. A criação dos elementos

PILLAR, Analice Dutra; MEDEIROS, Rosana Fachel de. 419

Artes Visuais na Pedagogia: atelier de criação de bonecos de pano.

Revista GEARTE, Porto Alegre, v. 8, n. 2, p. 415-433, maio/ago. 2021.

Disponível em: http://seer.ufrgs.br/gearte 


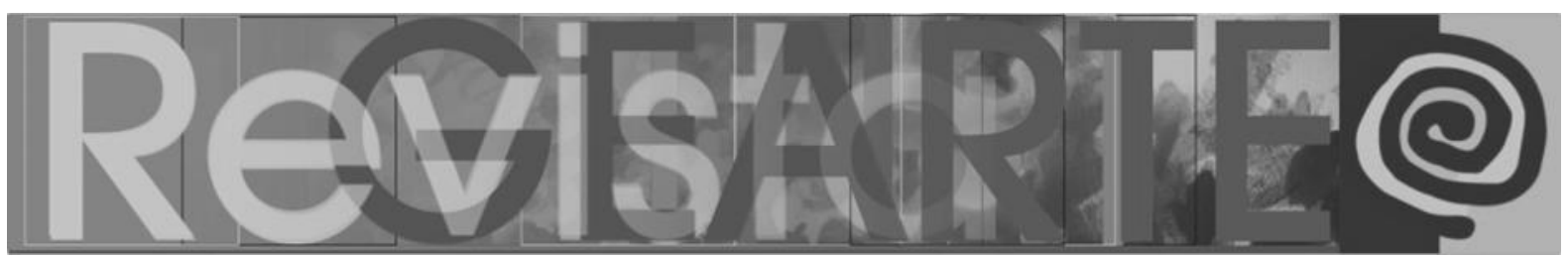

faciais, de cabelos, de adereços de cabeça (como chapéus, lenços, turbantes, fitas), as vestimentas e os acessórios vão caracterizando e dando singularidade a cada personagem criado. Pode-se, também, acrescentar adereços com tricô, crochê e bordado.

Outra alternativa consiste em dar forma à cabeça do boneco, ou seja, colocar os elementos do rosto, como olhos, nariz e boca (colados ou costurados), para depois decidir o tipo de cabelo da figura e, após, finalizar a cabeça, estruturar o corpo e as extremidades. São modos de construção, um partindo do todo e depois detalhando as partes e outro partindo das partes para depois estruturar o todo. Estamos, assim, trabalhando com volumes e com objetos tridimensionais, utilizando agulha e linha, às vezes, pela primeira vez, cola quente ou apenas amarrações.

\section{Bonecos criados pelos estudantes}

Dessa provocação com os materiais e da proposta surgem vários bonecos brancos, negros, coloridos, com cabelos trançados, com luzes nos cabelos, bonecos magros, outros gordos, bonecos idosos, noivas, super-heróis, princesas, bruxas. Alguns utilizando costuras, outros usando cola quente, outros colados com fitas ou amarrados. A criação suscita reflexões tanto em relação à confecção como ao tipo de boneco. Pode-se observar que, em geral, os estudantes negros procuram criar bonecos negros, evidenciando uma representatividade que muitas vezes não tiveram na infância. As figuras 9 a 28 trazem alguns desses bonecos produzidos pelos estudantes. 


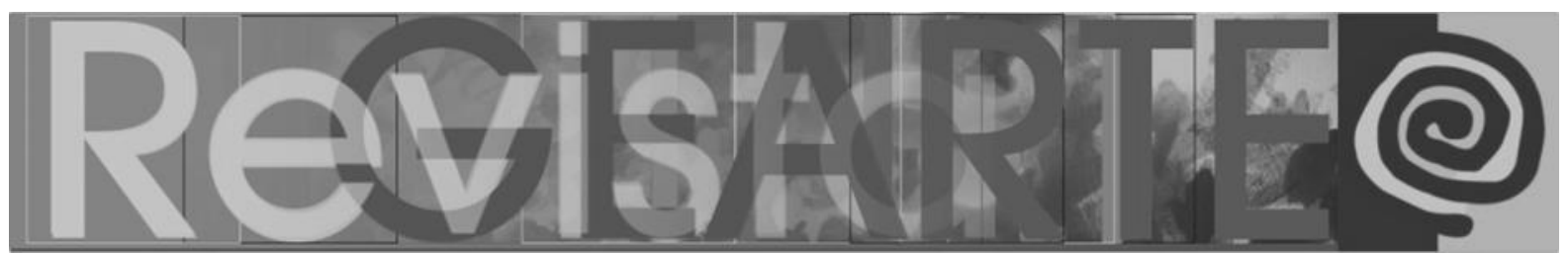

Figuras 9 a 28 - Bonecos de pano criados pelos estudantes
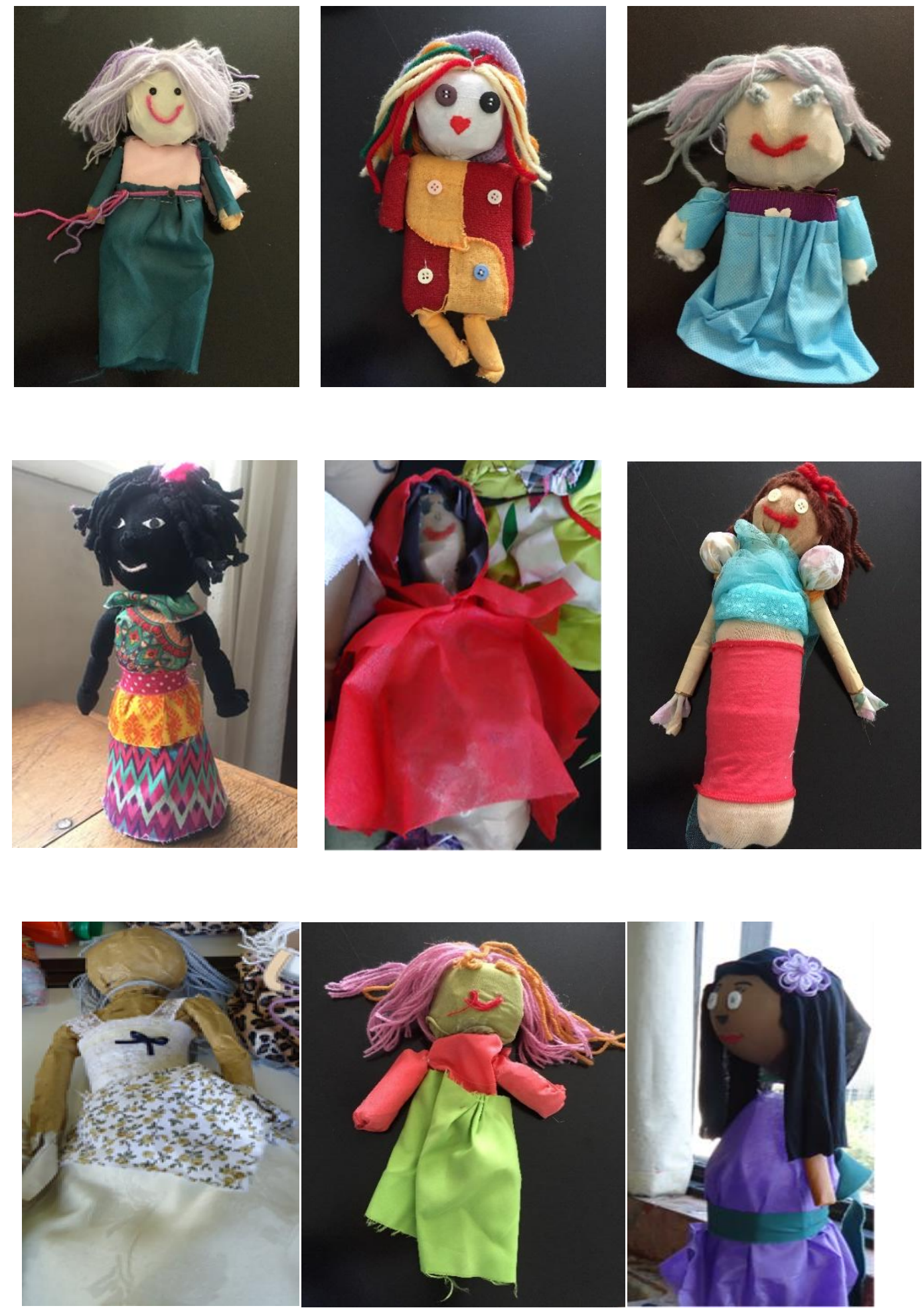

PILLAR, Analice Dutra; MEDEIROS, Rosana Fachel de.

Artes Visuais na Pedagogia: atelier de criação de bonecos de pano.

Revista GEARTE, Porto Alegre, v. 8, n. 2, p. 415-433, maio/ago. 2021.

Disponível em: http://seer.ufrgs.br/gearte 

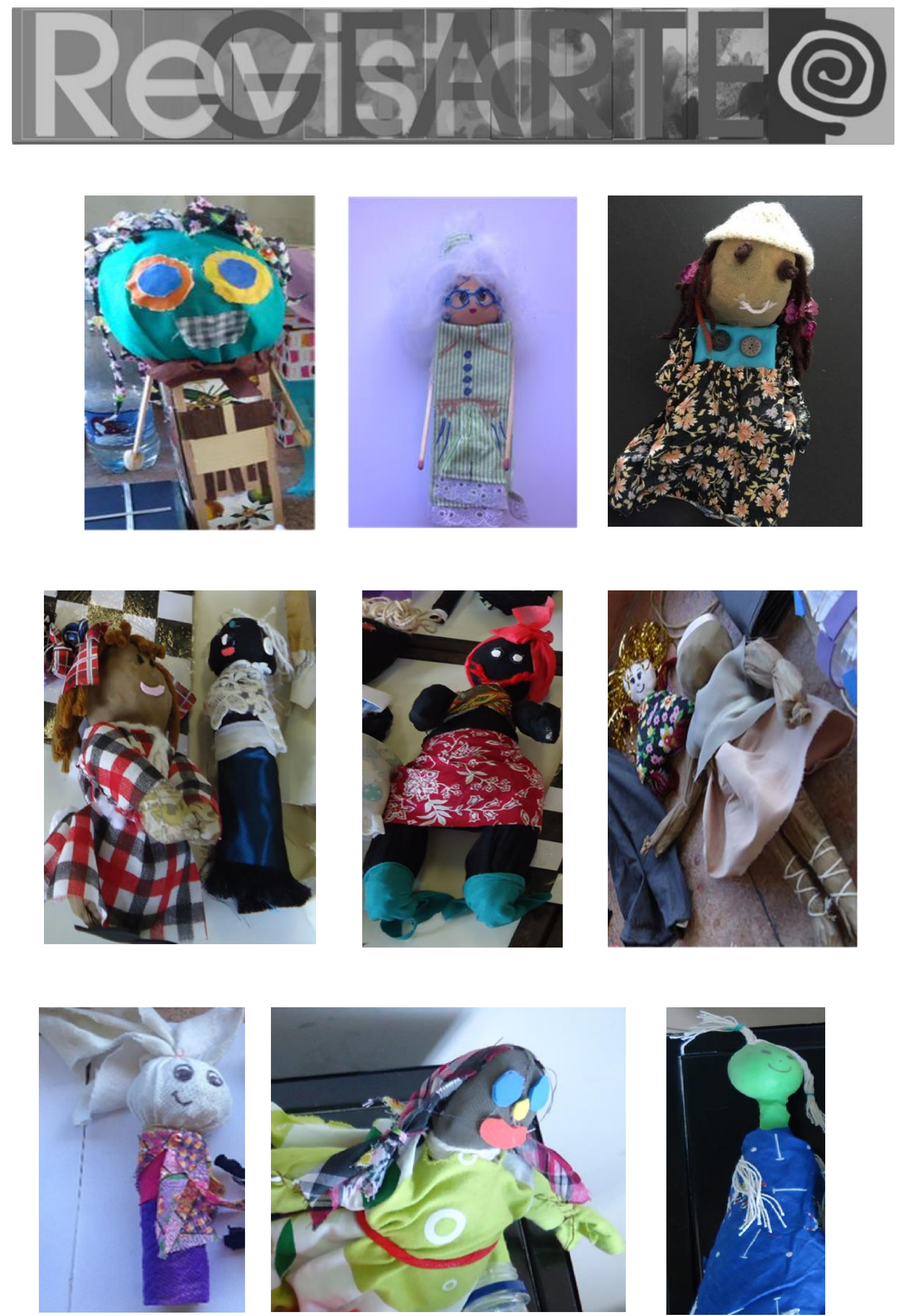

PILLAR, Analice Dutra; MEDEIROS, Rosana Fachel de.

Artes Visuais na Pedagogia: atelier de criação de bonecos de pano.

Revista GEARTE, Porto Alegre, v. 8, n. 2, p. 415-433, maio/ago. 2021.

Disponível em: http://seer.ufrgs.br/gearte 

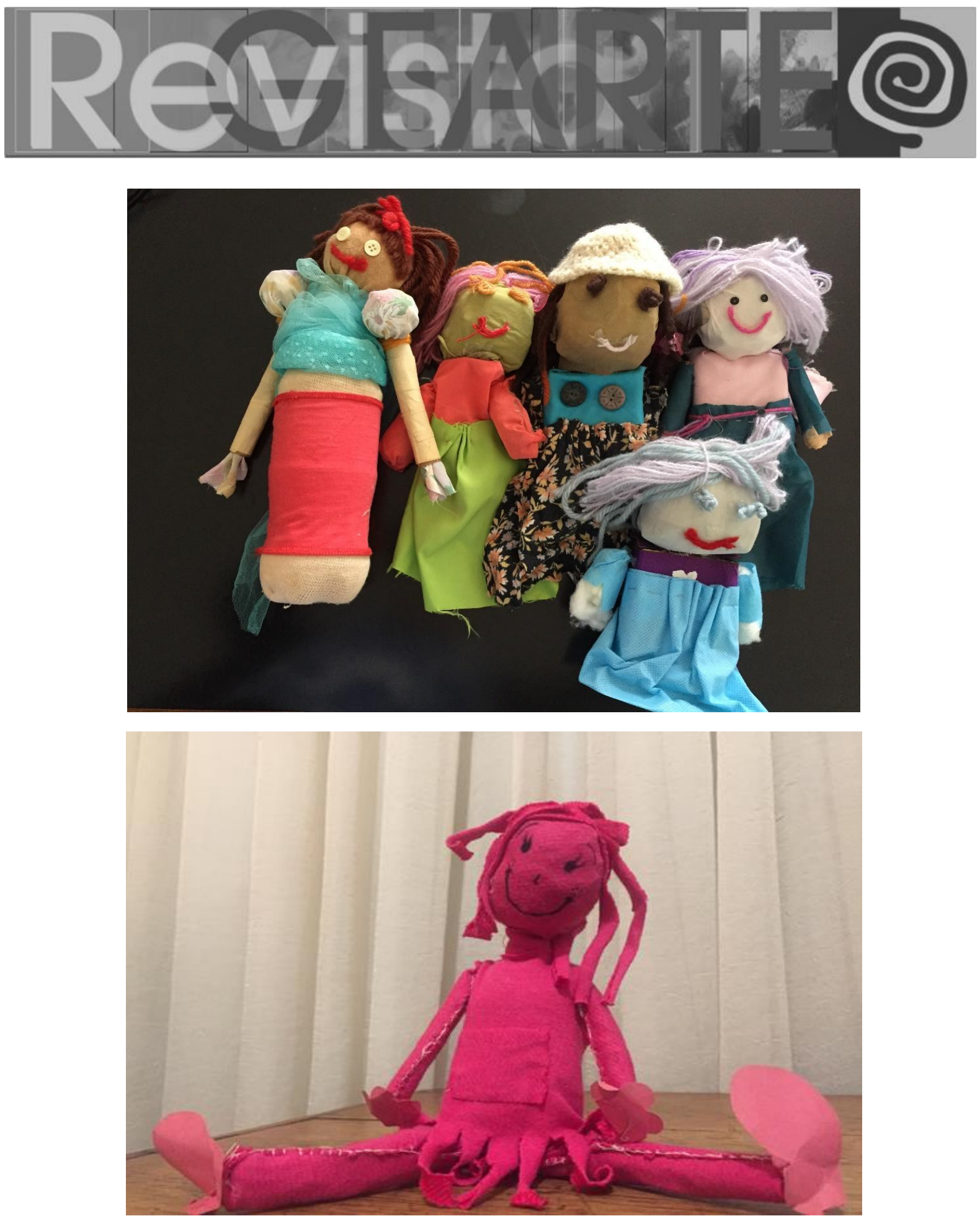

Fonte: Arquivo das autoras, 2020.

As possibilidades de criação de bonecos são muitas. Pode-se utilizar somente a amarração de tecidos, como a Abayomi, a boneca negra feita com cinco nós, a qual historicamente foi criada pelas mães africanas que vieram nos navios da diáspora negra e que faziam as bonecas com tiras de tecidos de suas saias. Há, aqui, duas questões importantes para refletir: o contexto histórico de criação 


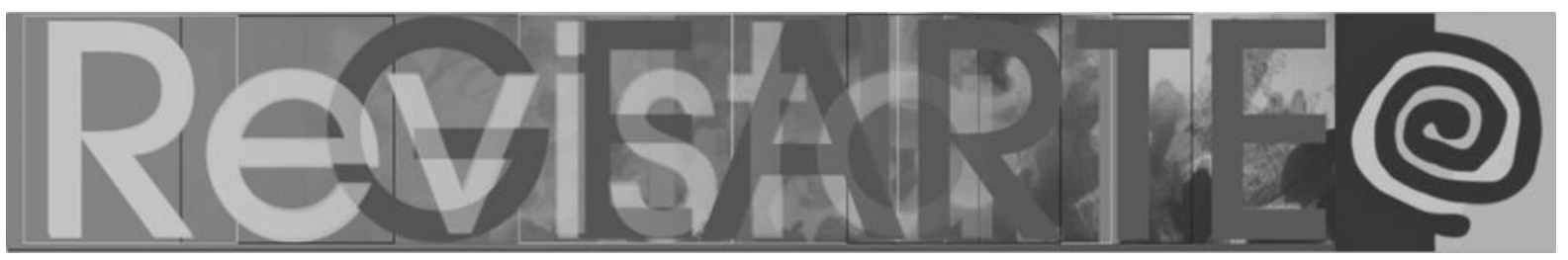

da Abayomi e a construção de bonecas negras, que estão pouco presentes nas lojas de brinquedos, tanto no Brasil como em outros países. Isso porque

Gerar em cada pessoa uma confiança baseada na apreciação profunda de sua própria cultura é o melhor ponto de partida possível para explorar, respeitar e apreciar outras culturas. Para isso, é vital perceber o caráter constantemente mutante da cultura e seu valor em contextos tanto históricos como contemporâneos. ${ }^{6}$ (CONFERÊNCIA MUNDIAL SOBRE LA EDUCACIÓN ARTÍSTICA, 2006, p. 5, tradução nossa)

Ao propiciarmos a criação de bonecos, estamos considerando os contextos diferenciados dos estudantes de uma turma de graduação em Pedagogia que serão futuros professores de crianças, de adolescentes, de jovens e adultos, de pessoas com necessidades especiais e, também, nos mais variados contextos, seja na rede pública, na rede particular de ensino, em comunidades indígenas, em hospitais, instituições penais ou em ONGs. Respeitar a diversidade social, de etnias, de idades e de gêneros dessa turma, acolher e possibilitar que expressem seus interesses e suas estéticas na construção de bonecos resulta em produções bem diversas e criativas. Nos últimos anos, alguns estudantes fizeram Abayomis, produziram várias bonecas negras, umas com turbantes coloridos, outras com cabelos amarrados acima da cabeça, em geral, várias bonecas de tamanhos diferentes, como se fosse uma família (conforme as figuras 29 a 31).

Figuras 29 a 31 - Abayomis criadas pelos estudantes
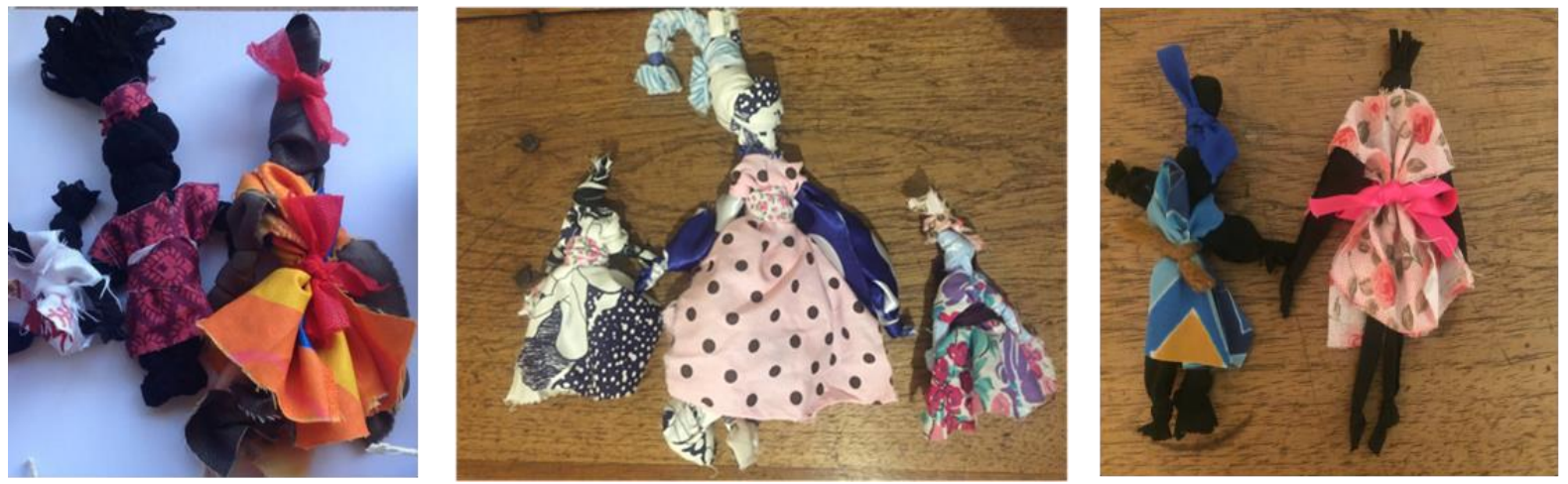

Fonte: Arquivo das autoras, 2020.

Outra possibilidade de construção de bonecos é com o uso do fuxico. O fuxico é uma técnica artesanal que consiste em construir algo a partir do 


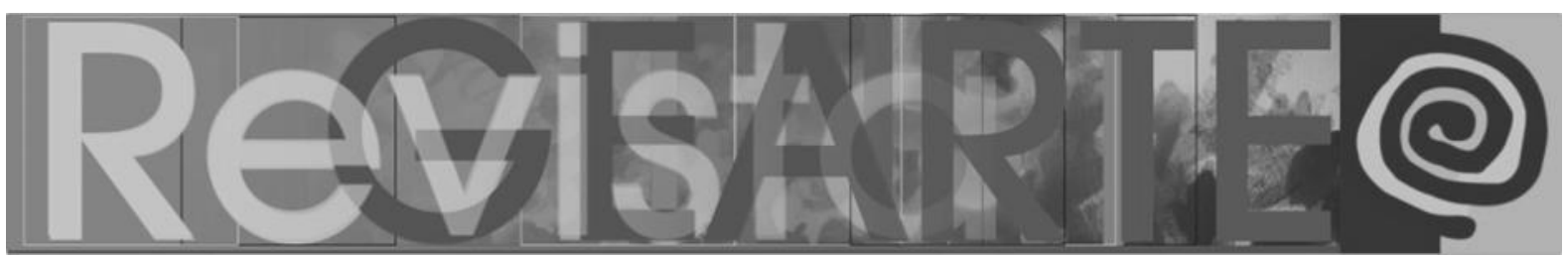

aproveitamento de retalhos de tecidos. O fuxico pode ser feito com pequenos círculos, com um alinhavo em volta, o qual, ao ser puxado, forma uma trouxinha de tecido. Outro tipo de fuxico é aquele que, a partir de um círculo dobrado ao meio e depois novamente, é alinhavado na parte mais larga, a qual, ao ser puxada, forma uma pétala. Os bonecos, em geral, são construídos com diversas trouxinhas coloridas para o corpo, para os braços e as pernas.

O fuxico em forma de trouxinha é muito usado no artesanato, na moda e na decoração. Podemos ver o fuxico em forma de pétala em adereços para cabeça, colares e broches. Não se sabe a origem do fuxico, mas estudos mostram que, no Brasil, teve origem no período colonial, através do aproveitamento de retalhos de tecidos.

\section{Olhando a diversidade}

Após a criação dos bonecos, esses são colocados em exposição para que se possa observar e conversar sobre o conjunto das produções, sobre o modo como os materiais foram utilizados, sobre a diversidade dos bonecos e sobre os tipos de construções. Os estudantes têm destacado o aproveitamento de materiais - retalhos de tecidos de diversas cores, estampas e texturas, rendas, meias, botões, fitas, linhas, lãs e jornais - como uma forma de realizar esta proposta sem precisar comprar materiais específicos e, principalmente, de criar a partir do que se tem disponível. Numa sociedade em que tudo é descartável, reutilizar materiais que seriam desprezados ou jogados fora, para invenção de outros objetos é uma atitude sustentável.

Nas conversas, os estudantes destacaram a importância da proposta ser apenas um disparador para que surgissem diversas maneiras de construção dos bonecos. A grande variedade das produções mostra as singularidades de cada grupo de estudantes, a acolhida do diferente, de bonecos com diversos tipos físicos. Os bonecos negros, os cabelos coloridos, os velhinhos, personagens das histórias são ressaltados nos comentários. María Acaso (2006) considera a 


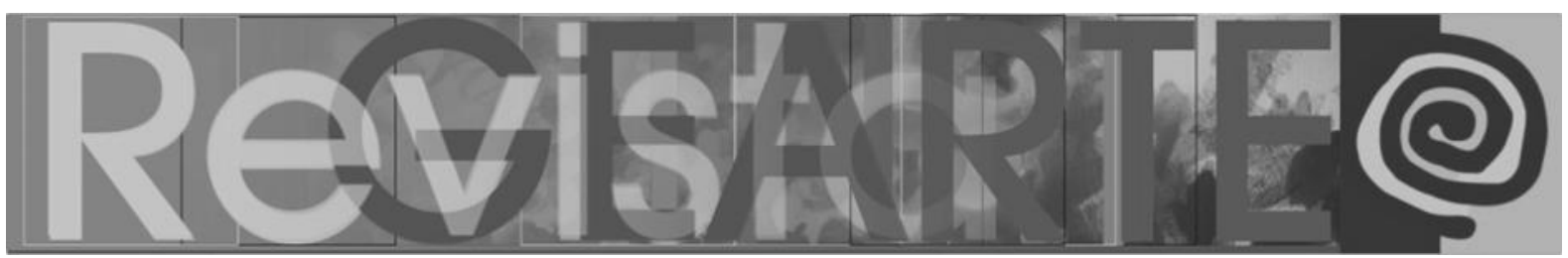

importância de produções visuais que procuram romper com os estereótipos e fomentar a diversidade visual.

Ao olharmos os bonecos, procuramos ver como cada um foi construído, que tipo de estrutura foi utilizada para o corpo e para os membros, como foram feitas as características do rosto - olhos, nariz, boca, sobrancelhas, cílios - , que expressões faciais surgiram e que acessórios foram colocados. É um momento de grande troca de experiências e de percepção daqueles que foram concebidos de modo mais plano, de outros mais em volume, dos que têm membros articulados. São apontadas, também, características de gênero nos bonecos e comentado que não são produções somente a serem feitas por meninas ou por mulheres.

Em geral, os estudantes mencionam o entusiasmo da turma durante a criação dos bonecos, as trocas de ideias e de informações com os colegas, a busca no celular por referências - principalmente nos últimos anos -, e a vontade de realizar com seus alunos tal proposta. Em relação às propostas para os alunos, ressaltamos a importância de adequar à idade, ao contexto e às possibilidades de cada grupo, seja na Educação Infantil, nos anos iniciais do Ensino Fundamental, na Educação de Jovens e Adultos ou com pessoas com necessidades especiais.

\section{Dialogando com obras de artistas com bonecos}

De modo a relacionar o trabalho realizado na aula com produções da arte contemporânea, procuramos apresentar aos estudantes imagens de obras de artistas que têm por tema bonecos. Uma produção audiovisual que mostramos foi sobre a exposição Labirinto da Moda: uma aventura infantil, que ocorreu em São Paulo, no SESC Pompéia, em 1995. Nessa exposição havia painéis com bonecos de pano feitos por artesãos de diferentes estados do país, por internas do hospital psiquiátrico Colônia Juliano Moreira, por bonequeiros profissionais, bem como com coleções de bonecos antigos, de louça e de origem europeia. 


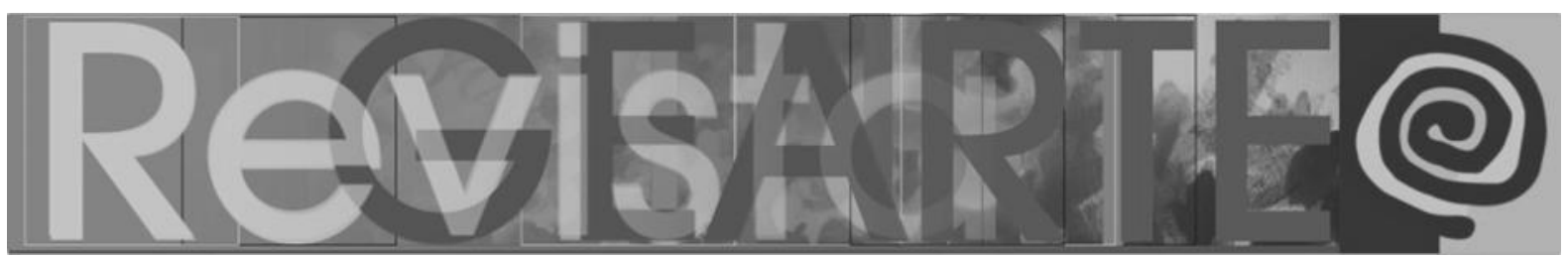

Um outro trabalho que apresentamos foi o de Lia Menna Barreto, que em 1998, criou o projeto Diário de uma Boneca, o qual consistia em confeccionar uma boneca a cada dia do ano. Dependendo do tempo disponível para construir a boneca, esta ficava mais elaborada ou mais sintética. No final foram expostas todas as 400 bonecas do projeto. Conforme a artista, "[...] o Diário começou com a decisão de fazer uma boneca por dia. Durou pouco mais de um ano." ${ }^{7} \mathrm{Em} 2019$, foi lançado o livro Diário de uma boneca (MENNA BARRETO, 2019), com lindas fotos das produções e, na mesma época, a obra foi doada para a Fundação Vera Chaves Barcellos, para compor a coleção Artistas Contemporâneos. Nas figuras 32 e 33, que seguem, podemos ver algumas dessas bonecas em parte do conjunto.

Figuras 32 e 33 - Fotos de detalhes do Diário de uma boneca de Lia Menna Barreto

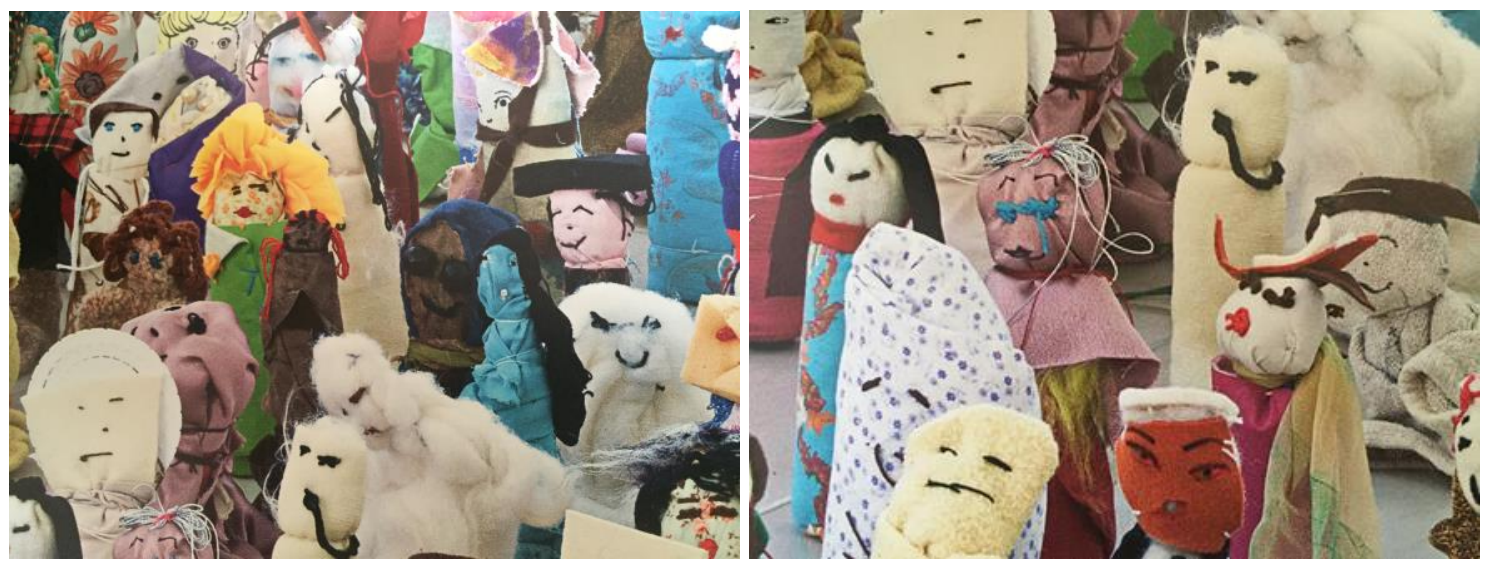

Fonte: Fotos das autoras a partir de detalhes de fotos do livro Diário de uma boneca, 2020.

Ao longo dos anos em que realizamos esta proposta, vários artistas foram mencionados, como Johnny Beinart ${ }^{8}$, escultor australiano, que monta obras utilizando bonecos de plástico que são recortados e articulados. Outro artista que referimos foi Chris Jordan ${ }^{9}$, artista americano que usa bonecas Barbie para criar obras que criticam o consumismo exacerbado dos estadunidenses. Jordan criou uma obra que configura um torso feminino usando 32.000 bonecas, fazendo alusão ao número de cirurgias de implante de silicone mamário mensal nos EUA.

Um outro material apresentado aos estudantes foi o livro De muñueca estereotipada a gente 'normal', de Pilar Pérez, no qual a autora traz um trabalho 


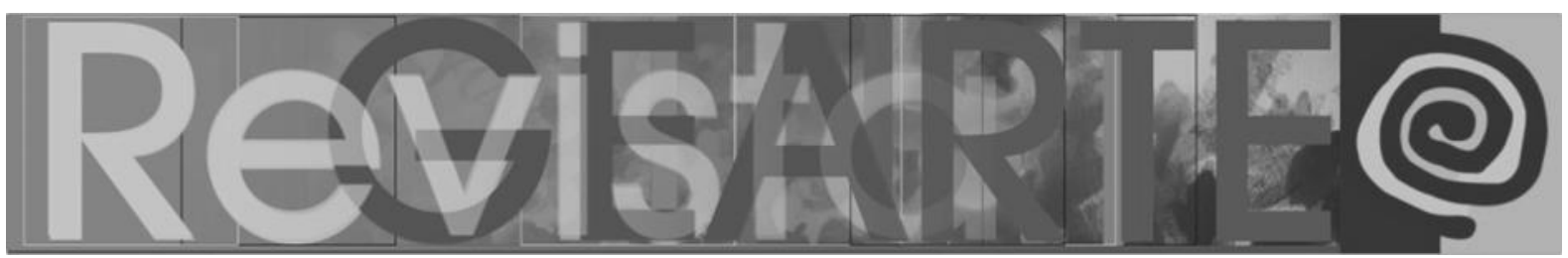

realizado pelos estudantes da Facultad de Profesorado da Universidad Autónoma de Madrid. A proposta era transformar uma boneca estereotipada (Barbie, Bratzs, Monster High, Bratzillaz, Minnie Fashion, Giochi Preziosi) em outra normal, isto é, com aspectos culturais importantes para construção da identidade de gênero em determinado contexto. Conforme Pérez (2016) menciona "[...] a experiência das transformações foi inspirada no trabalho da artista Tasmania Sonia Singh, que modifica bonecas estereotipadas em outras 'normalizadas' e as vende nas redes sociais." ${ }^{10}$ (PÉREZ, 2016, p. 4, tradução nossa).

No mercado, podemos encontrar bonecos de pano feitos de forma estereotipada, mas o que nos interessa com esta proposta é dar espaço para a diversidade e para a criação de bonecos que tragam marcas da nossa cultura e do contexto dos estudantes. Assim, são criados bonecos de diversas idades, etnias, tipos de cabelo, super-heróis, personagens de contos de fadas e de desenhos animados, bruxas. E, ainda, propiciar que tanto meninas como meninos e tanto mulheres como homens possam criar bonecos de pano, pois não se trata de uma atividade restrita ao gênero feminino.

Ao encaminhar esta proposta para crianças, adolescentes, jovens e adultos, em diferentes contextos, importa considerar as especificidades de cada grupo. Ao trabalhar com crianças pequenas, dependendo da idade, o uso de agulha e linha, bem como de cola quente não são adequados, portanto, é melhor usar cola líquida ou fazer bonecos com amarrações. Com crianças dos anos iniciais do Ensino Fundamental é possível utilizar linha e agulha para costurar os bonecos. Já com adolescentes e adultos, o uso da cola quente, da linha e agulha, bem como de bordados, crochê e tricô têm boa receptividade.

\section{Alinhavando os pontos: a Arte na Pedagogia e a Pedagogia da Arte}

A presença da disciplina Educação e Artes Visuais na grade curricular do curso de Licenciatura em Pedagogia da UFRGS tem um papel importante na formação dos futuros professores. Primeiro, para que ressignifiquem e ampliem 


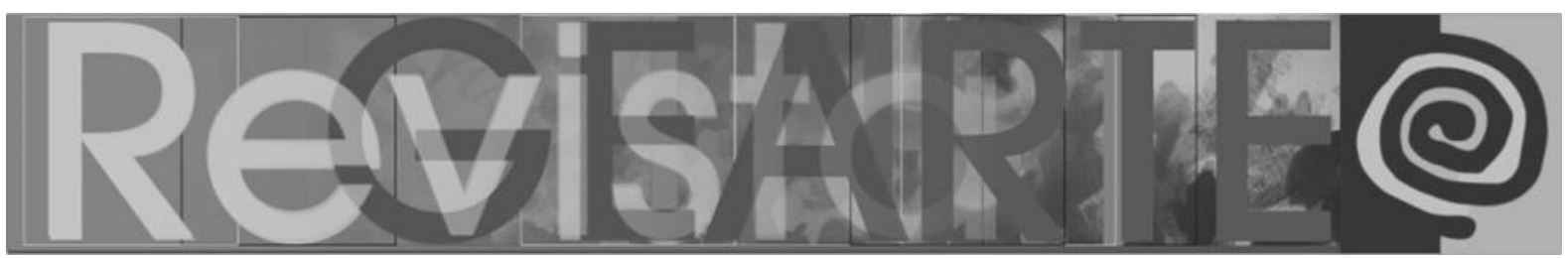

suas vivências como estudantes de Educação Artística na Educação Básica, de modo a tornarem suas aulas de artes relevantes. Durante as aulas, ainda, é recorrente, nas falas dos graduandos, a lembrança de aulas bastante tradicionais, nas quais tinham que colorir desenhos xerocados, ou reproduzir modelos prontos. Nesse sentido, a disciplina procura, com seu caráter teórico/prático, oportunizar aos estudantes a reflexão em relação ao ensino das artes visuais, como também viabiliza diferentes momentos de criação como, por exemplo, a confecção de bonecos de pano.

Essa experiência de vivenciar o processo de criação em diferentes linguagens artísticas, de analisar o que foi feito e de relacionar a proposta realizada com trabalhos de artistas, com outras imagens dá a esses estudantes, futuros professores da Educação Infantil, dos Anos Iniciais ou da Educação de Jovens e Adultos, subsídios teóricos e práticos para que possam oportunizar aulas de artes consistentes, atrativas e inventivas. Tendo em vista que, como bem alerta Barbosa (2005, p. 18) "[...] temos professores dando aula de artes que nunca leram nenhum livro de arte-educação e pensam que arte na escola é dar folhas para colorir [...]".

A busca por aula de artes que favoreçam a criação em outras linguagens ficou evidente nessas reflexões de três estudantes ${ }^{11}$ : "[...] é importante sair da ideia de artes como apenas pintar e fazer cópias"; "Aprendi várias propostas de atividades, como fazer bonecos, brinquedos, massa para modelagem, tinta caseira; poder olhar o que fizemos; e um pouco de história da arte."; "Achei muito importante poder compreender melhor tudo o que esta aula pode abranger e as muitas possibilidades que tenho para expressar e trabalhar com meus alunos, desde o desenho até a construção de brinquedos".

As vivências de processos de criação na disciplina foram avaliadas de forma positiva pelos graduandos. De acordo com alguns deles: "Todas as atividades foram excelentes e, além de contribuir para a minha formação (profissional e pessoal), me proporcionou momentos leves, de criatividade e diversão"; "Acredito 


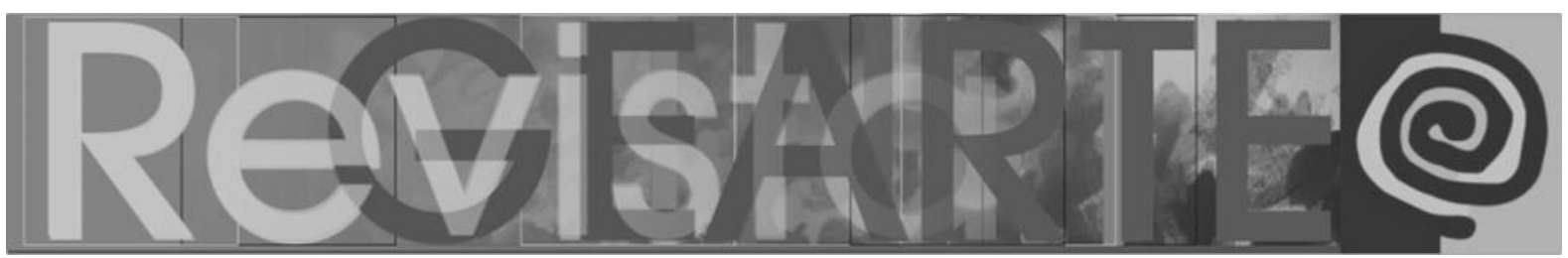

que a disciplina de artes é uma das únicas que possibilita ao aluno criar e se expressar, utilizar a sua criatividade". Outra estudante afirmou que o mais tocante da disciplina foi a oportunidade de experenciar e ver as possibilidades de criação nas atividades propostas e, ainda, complementou: "[...] sempre estudamos e escutamos como dar aula, mas nunca experenciamos as aulas pelas quais os nossos alunos irão passar". Esses comentários evidenciam a relevância que as atividades de criação ocupam nessa disciplina.

Dentre os ateliers realizados durante as aulas, destacamos, para esse texto, o atelier de criação de bonecos de pano. Esse espaço de confecção de bonecos singulares e diferentes se mostrou uma experiência desafiadora e, também, bastante prazerosa. O desafio estava no fato de muitos dos estudantes nunca terem realizado tal tipo de construção, então, a satisfação se deu no momento que eles conseguiram finalizar com êxito a proposta. Além disso - e para nós o que foi mais significativo -, muitos estudantes se viram representados nos bonecos criados, já que surgiram bonecos de óculos, magros, gordos, e, muitos bonecos negros, feitos, principalmente, por graduandos negros. Essa representatividade é de extrema importância quando levamos em consideração a reiteração de padrões de beleza nos bonecos industrializados.

Para finalizar, gostaríamos de reiterar a importância de disciplinas de Arte ${ }^{12}$ nos cursos de Pedagogia, uma vez que, na maior parte das escolas brasileiras, é o pedagogo o professor responsável por apresentar as linguagens da Arte para os alunos da Educação Infantil, dos Anos Iniciais e da Educação de Jovens e Adultos. Consideramos imprescindível vivenciar o processo criativo em diferentes linguagens artísticas, realizar a leitura dos trabalhos e relacionar as propostas feitas com produções artísticas para compreender suas possibilidades e sua importância na educação em diferentes contextos. A arte tem a capacidade de nos mobilizar, de propiciar um olhar atento às diferenças, de nos colocar no lugar do outro, de aprimorar a nossa sensibilidade, a nossa percepção e de nos transformar. 


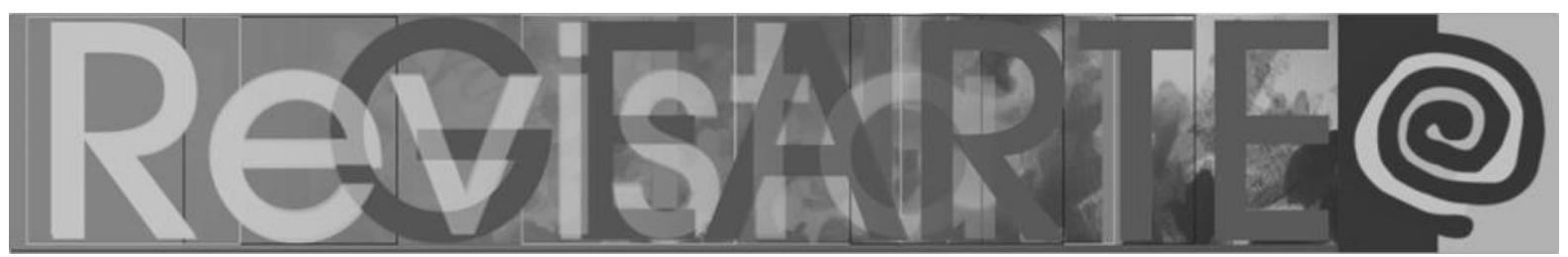

\section{Notas}

1 "Barbie é mais do que apenas uma boneca. A marca tem 1 bilhão de dólares em vendas em mais de 150 países anualmente." Informações disponíveis em GERALDO [2016?]. Acesso em: 6 abr. 2020.

2 Informações disponíveis em GERALDO [2016?]. Acesso em: 6 abr. 2020.

3 Informações disponíveis em FERRARI (2020). Acesso em: 7 abr. 2020.

4 Texto original: "Cualquier enfoque de la educación artística debe tomar como base la cultura o culturas a las que pertenece la persona que aprende." (CONFERÊNCIA MUNDIAL SOBRE LA EDUCACIÓN ARTÍSTICA, 2006, p. 5)

5 A disciplina Educação e Artes Visuais é oferecida no terceiro semestre do curso de Licenciatura em Pedagogia, como obrigatória, com uma duração de 45 horas/aula, e, nos últimos anos, em função da política de quotas, tem recebido estudantes indígenas e um número maior de estudantes negros.

6 Texto original: "Generar en dicha persona una confianza basada en la apreciación profunda de su propia cultura es el mejor punto de partida posible para explorar, respetar y apreciar otras culturas. Para ello, es vital percibir el carácter constantemente cambiante de la cultura y su valor en contextos tanto históricos como contemporáneos." (CONFERÊNCIA MUNDIAL SOBRE LA EDUCACIÓN ARTÍSTICA, 2006, p. 5)

7 Informação disponível em MENNA BARRETO (2019). Acesso em: 8 abr. 2020.

8 Mais informações em ARTE (2007). Acesso em: 19 abr. 2020.

9 Mais informações em CHRIS (2008). Acesso em: 19 abr. 2020.

10 Texto original: "La experiencia de las transformaciones fue una inspiración de taller a partir del trabajo de la artista Tasmania Sonia Singh, que modifica muñuecas estereotipadas en otras 'normatizadas' y las vende en las redes sociales." (PÉREZ, 2016, p. 4).

11 Esses comentários dos estudantes foram transcritos de produções escritas realizadas durante a disciplina: Educação e Artes Visuais no segundo semestre de 2019.

12 No currículo do curso de Licenciatura em Pedagogia da Faculdade de Educação da Universidade Federal do Rio Grande do Sul fazem parte as disciplinas: Educação e Teatro, Educação Musical e Educação e Artes Visuais (como obrigatórias) e Educação e Dança (como alternativa).

\section{Referências}

ACASO, María. Esto no son las Torres Gemelas: cómo aprender a leer la televisión y otras imágenes. Madrid: Catarata, 2006.

AMARAL, Glaucia. Labirinto da Moda: uma aventura infantil. São Paulo: SESC Pompeia, 1996. Catálogo da exposição.

ARAÚJO, Anna Rita Ferreira de. Os cursos de pedagogia e o ensino da arte: aspectos legais e históricos. Trama Interdisciplinar, São Paulo, v. 6, n. 2, p. 37-58, maio/ago., 2015.

ARTE com brinquedo ou brinquedos usados na arte: esculturas do australiano Johnny Beinart. Ensinando Artes Visuais, [S.I.] 2007. Disponível em <http://ensinandoartesvisuais.blogspot.com/ 2007/10/o-australiano-johnny-beinart-desenha-e.html>. Acesso em jul 2021.

BARBOSA, Ana Mae. A imagem no ensino da arte: anos oitenta e novos tempos. 6. ed. São Paulo: Perspectiva, 2005.

PILLAR, Analice Dutra; MEDEIROS, Rosana Fachel de. 


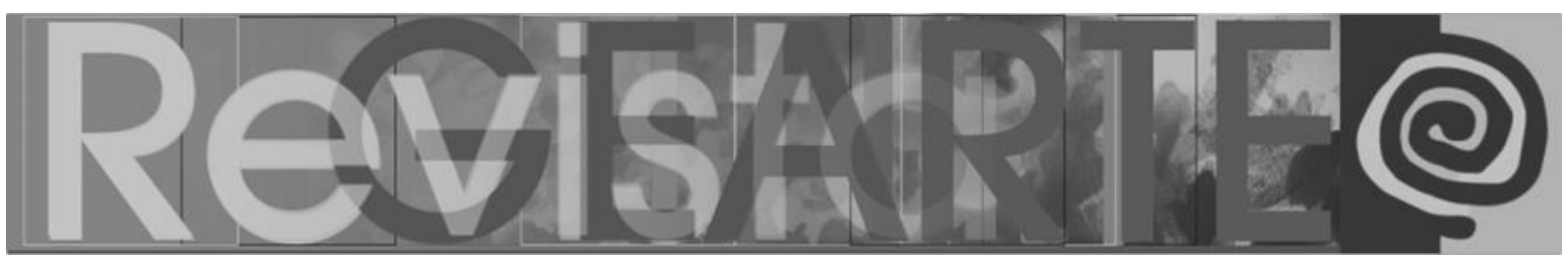

BAUMAN, Zygmunt. Los retos de la educación en la modernidad liquida. Barcelona: Gedisa, 2008. Disponível em: http://ciec.edu.co/wp-content/uploads/2017/06/Bauman-Zygmunt-Los-Retos-DeLa-Educacion-En-La-Modernidad-Liquida-1.pdf. Acesso em: 16 abr. 2021.

CHRIS Jordan - Fotografía y Activismo. Fotografía. Uno de los Nuestros, [S.I.], 2008. Disponível em <https://www.enkil.org/2008/10/20/chris-jordan-fotografia-y-activismo/>. Acesso em jul 2021.

CONFERÊNCIA MUNDIAL SOBRE LA EDUCACIÓN ARTÍSTICA: construir capacidades creativas para el siglo XXI. 6-9 mar. 2006, Lisboa. Hoja de Ruta para la Educación Artística. Lisboa: UNESCO, 2006. Disponível em: <http://www.unesco.org/new/fileadmin/MULTIMEDIA/HQ/CLT/CLT/ pdf/Arts_Edu_RoadMap_es.pdf.> Acesso em: 7 abr. 2020.

FERRARI, Mariana. Diversidade que vende. Comportamento. Isto é, [S.I.], 2020. Disponível em: $<$ https://istoe.com.br/diversidade-que-vende/>. Acesso em jul 2021.

GERALDO, Nathália. Veja todas as 33 novas Barbies: baixinha, gordinha, negra. Qual se parece com você? Mulher. Vix [S.I.] [2016?]. Disponível em: <https://www.vix.com/pt/bdm/comportamen to/veja-todas-as-33-novas-barbies-baixinha-gordinha-negra-qual-se-parece-com-voce>. Acesso em jul 2021.

LIPOVETSKY, Gilles. A felicidade paradoxal: ensaio sobre a sociedade de hiperconsumo. São Paulo: Companhia das Letras, 2007.

MENNA BARRETO, Lia. "Diário de Uma Boneca" 1998. Coleções, [S.I], 2019. Disponível em: $<$ https://lia-mennabarreto.blogspot.com/2019/05/diario-de-uma-boneca-1998-pertence-ao.html>.

Acesso em: 15 abr. 2020.

MENNA BARRETO, Lia. Lara e o "Diário de Uma Boneca" 1998-2018. [S.I.], 2018. Disponível em: $<$ https://lia-mennabarreto.blogspot.com/2018/06/lara-e-o-diario-de-uma-boneca-2018.html>.

Acesso em: 15 abr. 2020.

MENNA BARRETO, Lia. Diário de uma boneca. Porto Alegre: Libretos, 2019.

OLIVEIRA, Ana Claudia Mei Alves de. Da boneca às bonequinhas: uma mesma imagem de construção do corpo. Revista deSignis, v. 1, p. 159-167, 2001.

OLIVEIRA, Manoella. Por que a diversidade das bonecas importa. Infância. Deustche Welle [S.I.], 2019. Disponível em: <https://www.dw.com/pt-br/por-que-a-diversidade-das-bonecas-importa/a47586054> Acesso em jul 2021.

PÉREZ, Pilar. (org.). De muñeca estereotipada a gente 'normal'. Madrid: Universidad Autónoma de Madrid, 2016.

\section{Analice Dutra Pillar}

Professora Titular da Faculdade de Educação da Universidade Federal do Rio Grande do Sul (FACED/UFRGS), Brasil, na área de ensino de artes visuais no curso de Pedagogia e no Programa de Pós-Graduação em Educação. Doutora em Artes pela Escola de Comunicações e Artes da Universidade de São Paulo (ECA/USP), mestre em Artes pela ECA/USP e graduada em Artes Plásticas pelo Instituto de Artes da UFRGS. Realizou Estágio de Pós-Doutorado na Universidad Complutense de Madrid. Pesquisadora do CNPq. Coordena o Grupo de Pesquisa em Educação e Arte (GEARTE/UFRGS/CNPq). Possui publicações na área do ensino de artes visuais.

ORCID: https://orcid.org/0000-0003-2143-3406

E-mail: analicedpillar@gmail.com

Currículo: http://lattes.cnpq.br/0033345213407184 


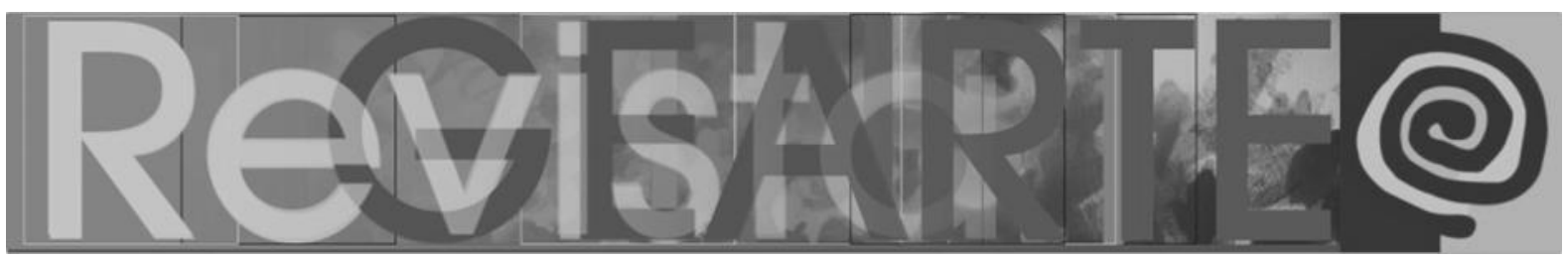

Rosana Fachel de Medeiros

Doutora em Educação e Artes Visuais pelo Programa de Pós-Graduação em Educação da Universidade Federal do Rio Grande do Sul (PPGEDU-UFRGS), mestre em Educação e Artes Visuais pelo PPGEDU-UFRGS, graduada em Pedagogia pela UFRGS - Habilitação Séries Iniciais e Habilitação Educação Infantil. Especialista em Educação Infantil. Realizou Estágio de PósDoutorado na UFRGS. Professora da Educação Básica ministra a disciplina de Artes no município de Canoas/RS. Membro do Grupo de Pesquisa em Educação e Arte (GEARTE/UFRGS/CNPq).

ORCID: https://orcid.org/0000-0002-2960-8517

E-mail: zanafachel@yahoo.com.br

Currículo: http://lattes.cnpq.br/4118891501254247

Recebido em 21 de fevereiro de 2021 Aceito em 15 de abril de 2021 